\title{
Making sense of one's actions in an explanatory vacuum: The interpretation of nonconscious goal striving
}

\author{
Elizabeth J. Parks-Stamm ${ }^{\mathrm{a}, *}$, Gabriele Oettingen ${ }^{\mathrm{a}, \mathrm{b}}$, Peter M, Gollwitzer ${ }^{\mathrm{a}, \mathrm{c}}$ \\ ${ }^{2}$ New York University, 6 Washington Place, 7 th Floor New York, NY 10003 \\ Universität Hamburg, Fachbereich Psychologie, Von-Melle-Park 5, D-20146 Hamburg, Cermany \\ CUniversität Konstanz, Fochbereich Psychologie, D.78457 Konstanz, Cemany
}

Keywords:

Explanatory vacuum

Nonconscious goals

Social norms

Automatic

\begin{abstract}
A B S T R A C T
Previous research has found that performing norm-violating behaviors based on a nonconsciously-activated goal elicits negative affect (Oettingen, Grant, Smith, Skinner, \& Gollwitzer, 2006). In the present research we explored whether this negative affect is eliminated when an earlier conscious goal with congruent behavioral effects can be used to explain the norm-violating behavior. Our findings suggest that applicable conscious goals are indeed used to interpret nonconsciously-activated goal striving (Study 1), and that this interpretation occurs reflexively rather than reflectively (Study 2), with implications for interpersonal behavior (Study 3). The role of social norms, applicable conscious goals, and negative affect in the interpretation of nonconscious goal purstut is discussed.
\end{abstract}

\section{Introduction}

One exciting aspect of research on nonconscious goal pursuit is the wide-ranging behavioral implications of nonconscious goals for daily social interactions: self-presentation goals activated at a party may produce unexpected behavior when one consciously intends to have fun (Bargh, 1990), or business-related items like briefcases or portfolios may activate competition goals unintentionally in a negotiation (Kay, Wheeler, Bargh, \& Ross, 2004). However, documenting the automatic behavioral responses to cues associated with goals is only the first step in understanding the consequences of nonconscious goal activation in thinking and feeling human beings. The current research examines how people explain goal-directed behavior when not aware of its cause. Are nonconsciously-activated goal-directed behaviors efficiently interpreted by the actor to form a coherent story? What are the implications of this interpretation (or the inability to interpret one's behavior for interpersonal behavior?

\section{Nonconscious goal activation}

A large body of research has documented that goals can be activated outside of awareness with goal-directed behavior then initiated without a conscious intention (summaries by Chartrand, Dalton, \& Cheng, 2007; Fishbach \& Ferguson, 2007; Gollwitzer \&

\footnotetext{
* Corresponding author.

Email address: ejp2340nyu.edu (E.J. Parks-Stamm).
}

Bargh, 2005). In his Auto-Motive theory, Bargh (1990) proposed that because goals are mental representations (like traits and stereotypes), they should be capable of activation through relevant cues. Chartrand and Bargh (1996) found evidence for this idea by exposing participants with impression or memorization goal-related words, processing goals typically associated with organized vs. less organized recall of behaviors, respectively. Participants primed with impression formation goal-related words were more likely to organize these behaviors by categories than those primed with a memorization goal, demonstrating that processing styles associated with nonconsciously-activated goals can mirror that of consciously-activated goals.

Subsequent research has extended the analysis of impression formation goals by examining complex behavioral goals. The nonconscious activation of such goals has consistently resulted in the behavioral responses expected from conscious goal striving, including achievement goals (Bargh, Gollwitzer, Lee-Chai, Barndollar, \& Troetschel, 2001, Study 1), competition goals (Bargh et al., 2001. Study 2; Kay et al, 2004), egalitarian goals (Moskowitz, Gollwitzer, Wasel, \& Schaal, 1999), interpersonal goals (Fitzsimons \& Bargh, 2003; Shah, 2003), and even cleaning goals (Holland, Hendriks, \& Aarts, 2005). In addition to eliciting similar behavioral outcomes, nonconsciously-activated goals exhibit the motivational qualities traditionally considered to be characteristics of conscious goal striving (Gollwitzer, 1990; Gollwitzer \& Moskowitz, 1996; Lewin, 1951). Using paradigms designed to examine classic goal features, Bargh and colleagues (2001) found that the activation of nonconsciouslyactivated goals increased in strength over time until acted upon 
(Study 3), produced persistence when obstacles were encountered (Study 4), and brought about resumption of goal-directed behaviors following interruption (Study 5). These studies suggest that nonconsciously-activated goals produce goal striving with the same cognitive, behavioral, and motivational features expected from goal striving that is instigated by consciously-set goals.

Researchers have further expanded our understanding of nonconscious goal pursuit by exploring what types of cues can activate relevant goals. In addition to semantic priming through words associated with the goal (e.g. "success" for the activation of a high performance goal; Bargh et al., 2001), goals have been nonconsciously activated through means (e.g. "running" to activate a fitness goal; Shah \& Kruglanski, 2003) and temptations (eg. "television" to activate a scholastic achievement goal; Fishbach, Friedman, \& Kruglanski, 2003), pictures of environments associated with norms (e.g., photos of a library to activate a quietness goal, as measured by voice volume; Aarts \& Dijksterhuis, 2003), and inanimate objects associated with situational norms (e.g., the presence of a briefcase to activate a competition goal; Kay et al., 2004). These studies have shown that goals can be activated through priming various constructs associated with the goal.

The activation of goals does not only occur through primes presented to participants in the laboratory; relevant goals may also be activated outside of awareness by other individuals in the social environment. Merely thinking about significant others can activate the goals these individuals would like us to pursue (Fitzsimons \& Bargh, 2003; Shah, 2003). For example, Fitzsimmons and Bargh (Study 1) approached individuals waiting at the gate in an airport and asked them to answer a few questions about either a friend or a colleague. Activating the representation of a friend in this way activated the goals that participants normally pursue with these individuals (e.g., helping), leading to more offers to help the experimenter following the activation of a friend than a colleague. Thus, other individuals can activate goal striving outside of awareness. On the other hand, Chartrand, Dalton, and Fitzsimons (2007) found that participants sometimes nonconsciously rejected the goals of controlling significant others, instead pursuing opposing goals, particularly when they were high in chronic reactance. Others can also nonconsciously activate those goals in us that are pursued by these others. Aarts, Gollwitzer, and Hassin (2004) refer to this phenomenon as goal contagion; they found that individuals automatically adopt and pursue goals implied by others' behaviors, as long as the implied goals are contextually and socially appropriate This research suggests that goals can be nonconsciously activated in many ways, including through the mere presence of others, goal-relevant material objects, and semantic constructs associated with the goal.

\section{The affective consequences of nonconscious goal pursuit}

The first examination of the affective consequences of nonconscious goal pursuit examined the two emotions traditionally associated with goal pursuit: the pride associated with reaching a goal and the shame associated with failure to reach it (Atkinson, 1957). This work suggests the affective consequences of nonconscious goal pursuit can mirror that of conscious goal pursuit as well, with success and failure resulting in positive and negative "mystery moods," respectively (Chartrand, 1999). For example, Chartrand gave participants an impression formation goal either consciously or nonconsciously, and then provided them with a number of behaviors to remember about a target that were either consistent or inconsistent). This made it easier for some people to form an impression, and more difficult for others. She found that those with an impression formation goal-whether it was set consciously or nonconsciously-reported being in a better mood when they had received the consistent description (where they had presumably succeeded at their goal) than the inconsistent one (where they had presumably failed). Because only those in the conscious goal condition knew why they felt this way, Chartrand (1999) called the resulting pride or shame among those in the nonconscious goal priming condition "mystery moods." Riketta and Dauenheimer (2003) extended this line of research by showing that the research participants' mood and self-esteem improved when they were presented with an opportunity to fulfill a primed goal, as would be expected in conscious goal pursuit. These findings imply that the affective consequences of success or failure at conscious and nonconscious goal pursuit should be quite parallel.

However, recent research suggests that even successful goal pursuit can result in negative affect when the goal driving a normviolating behavior is inaccessible to the actor (i.e., when it is nonconsciously activated; Oettingen, Grant, Smith, Skinner, \& Gollwitzer, 2006). Whereas the affective consequences of successfully acting towards a conscious goal should always be positive, Oettingen and colleagues predicted the affective consequences of successfully acting towards a nonconscious goal would vary based on the appropriateness of the behavior in context. They hypothesized that behavior that could not be explained by referencing a conscious goal or a normative explanation (i.e., behavior in an "explanatory vacuum") would result in negative affect. This reasoning follows from research by McGraw (1987) examining accidental harmdoing (i.e., norm violations with no salient explanation), which suggests that negative affect is experienced when norm-violating behaviors lack an accessible justification.

Oettingen and colleagues (2006) therefore predicted that normviolating behavior would only result in negative affect when the goal driving that behavior was nonconscious, and therefore inaccessible to the actor. In a collaborative task with a partner, participants either consciously adopted or were nonconsciously primed with the goal to be accommodating (a norm-conforming goal), combative (a norm-violating goal), or were not given a goal (control). Regardless of whether the goals to be combative or accommodating were consciously adopted or nonconsciously primed, behavior was in line with the goal, replicating past nonconscious goal research. Most importantly, self-reported negative affect following this behavior supported the hypotheses: only participants with a nonconsciously-activated norm-violating goal reported heightened negative affect following the task.

Past research has found that inconsistency between one's behavior and normative standards feels aversive and therefore motivates interpretation (Elliot \& Devine, 1994; Stone \& Cooper, 2001). The work by Oettingen et al. suggests that behaving in a norm-violating way feels aversive only when it cannot be explained by a conscious intention to violate the norm. Individuals with a conscious intention may reference their conscious goal to explain norm-violating behavior, but those without such a conscious intention should be motivated to find an alternative explanation for their behavior, thereby reducing the negative affect associated with an explanatory vacuum. We suggest this motivation drives interpretive processes, which reflexively make use of plausible explanations for the behavior.

\section{Evidence for reftexive interpretation}

Long before goals were subliminally primed in psychology laboratories, the automaticity of interpretation of our own behavior was pondered by philosophers and neurologists intrigued by the seeming coherence of our subjective experience. James Sully observed that interpretive processes seem to occur immediately and outside of awareness, "In looking back on the past, we see no absolute gaps in the continuity of our conscious life... just as the eye sees no gap in its field of vision corresponding to the "blind spot' of the retina, but carries its impression over this area" (1891. 
p. 282). That we experience not only our visual input as complete but our consciousness as unitary provides evidence that the mind reflexively engages in interpretation.

Reflexive and reflective processes (Lengfelder \& Gollwitzer, 2001; Lieberman, Gaunt, Gilbert, \& Trope, 2002) differ in whether conscious, effortful thought is engaged, in whether the processes are "mindless" or "mindful" (Langer, 1989). Whereas reflexive decision making can occur without awareness or conscious control, reflective decision making makes use of deliberation or manipulation of known information. As Lieberman (in press) suggests, whereas reflexive processes feel spontaneous or intuitive to the actor (and the outcome is therefore experienced as unedited reality), reflective processes feel intentional and deliberate (and the outcome is therefore experienced as generated by the self).

The interpretation of our own behavior is often highly reflexive, as is seen in the behavior of clinical populations who engage in confabulation when explaining the causes of their own behavior. Hirstein (2005) defines confabulation as a false response without "the intent to deceive [or] knowledge contrary to what is claimed" (p. 2). It typically results from an epistemic failure, such as from memory impairment in Korsakoffs syndrome or severed interhemisphere communication in split-brain patients. In one clear example of this reflexive interpretation, Cooney and Gazzaniga (2003) describe a confabulating split-brain patient whose right (unspeaking) hemisphere was presented with the command to walk. Once the individual rose to walk, and the experimenter requested an explanation, the left hemisphere (responsible for language) automatically generated an interpretation of the behavior (e.g." "I wanted a soda"). Although this explanation was objectively false, it was experienced as true by the patient who generated it. Roser and Gazzaniga suggest, "the action of an interpretive system becomes observable only when the system can be tricked into making obvious errors by forcing it to work with an impoverished set of inputs, such as in the split brain or in lesion patients" (2004, p. 58).

However, a lack of knowledge about the inner processes guiding behavior is not limited to individuals with brain injuries. As Nisbett and Wilson have argued, many cognitive processes are outside of conscious awareness, and therefore healthy research participants also seem to be working with an impoverished set of inputs, basing their judgments on observable behaviors only (1977). The dissonance literature, for example, demonstrates how counter-attitudinal behaviors are interpreted reflexively as indicative of one's own attitudes (Festinger, 1957; Lieberman, Ochsner, Gilbert, \& Schacter, 2001). Just as confabulators freely share false memories, participants in early dissonance studies freely offered false explanations for their behavior (Nisbett \& Wilson, 1977). Because many cognitive processes are not accessible, people seem to form post hoc causal theories to explain their behavior when the cause is not readily apparent, without knowledge of this interpretive process. We therefore propose that behavior in an explanatory vacuum is not experienced as perplexing, but is interpreted reflexively by the actor. As Dennett has suggested, "It is not that they lie in the experimental situation, but that they confabulate; they make up likely sounding tales without realizing they are doing it; they fill in the gaps, guess, speculate, mistake theorizing for observing" (1982, p. 173).

\section{Interpreting behavior in an explanatory vacum}

We propose that as Dennett suggests above, individuals use "likely sounding" explanations to explain their behavior when the goal is nonconsciously activated and the behavior conflicts with situational norms. Because this interpretive process is reflexive, individuals are unaware of interpretive processes taking place, and the interpretation instead feels like simply an observed reality. As in the case of the split-brain patient who asserts that she is walking to get a soda, we propose that individuals may use accessible and plausible goals to explain their behavior without awareness of this reflexive explanatory process.

Because norm-violations without a salient explanation create negative affect (McGraw, 1987), people in an explanatory vacuum should be highly motivated to interpret and justify their behavior (Stone \& Cooper, 2001). Stapel and Koomen have found that when people are extramotivated to explain an ambiguous behavior, they will apply accessible information "more readily and more extensively" (2001, p. 916). We hypothesize that individuals in an explanatory vacuum are extramotivated to interpret their behavior, and will therefore use accessible goal information readily and extensively, settling for explanations that will merely suffice. Whether or not a goal is applicable depends on the behavioral consequences of the goal; only goals with congruent behavioral effects should be applicable and therefore used to interpret behavior in an explanatory vacuum.

An applicable goal may be useful for explanation although it does not actually impact behavior, as is the case with previouslyachieved goals which may then exhibit post-fulfilment inhibition (Förster, Liberman, \& Higgins, 2005). Although the motivational component of an applicable goal is likely to be deactivated once it is satiated, being aware of one's prior goal striving should still be possible (in that it is not completely forgotten). In fact, satiated goals must routinely be recalled in order to evaluate the degree with which one's goal striving has been successful and to compare the expected value of goal attainment to its actual value (i.e., to meet the task demands of the post-action phase as described in the model of action phases; Gollwitzer, 1990). We propose that even satiated goals may therefore be used to reflexively interpret otherwise inexplicable behavior.

How can we know that this reflexive interpretation has occurred, if reflexive processes are outside of conscious awareness and too fast to be observed? Because individuals are motivated to reduce aversive states (e.g. guilt, Ketelaar \& $A u, 2003$; negative affect from inconsistency, Elliot \& Devine, 1994), placing participants in an explanatory vacuum (i.e., by nonconsciously priming norm-violating behavior) should allow us to examine interpretation via negative affect, ${ }^{1}$ without relying on participants' awareness of automatic interpretive processes. We propose that it is only by the absence of negative affect (otherwise expected in an explanatory vacuum) that we may know that interpretation has taken place. If the norm-violating behavior is reflexively interpreted as resulting from an accessible and applicable goal, participants should not experience or report heightened negative affect. If participants cannot reflexively interpret their behavior (e.g., because no accessible goal information can explain it), heightened negative affect should be observed.

\section{Overview of the present studies}

In the three studies presented here, we explored the use of earlier, accessible goals to interpret nonconsciously-activated normviolating behavior. In Study 1 , we examined whether an earlier applicable goal would eliminate the negative affect typically associated with an explanatory vacuum. Participants pursuing a nonconscious (vs. conscious) norm-violating (vs. norm-conforming) goal were given an earlier accessible goal that either explained or did not explain their behavior. Negative affect was then measured to examine whether interpretation had taken place. In Study 2, we attempted to replicate this effect, and tested whether interpretation was achieved through a reflexive or reflective process, by

\footnotetext{
1 In this case, we mean the "core affect" described by Russell, that "can exist without being labeled, interpreted, or attributed to any cause" (2003, p. 148) as opposed to discrete negative emotions.
} 
manipulating deliberation. In Study 3, we examined the impact of individual differences on interpretation and its consequences for interpersonal behavior. In general, we predict participants engaging in nonconsciously-activated norm-violating behavior will use earlier goals, if applicable, to reduce the negative affect associated with an explanatory vacuum.

\section{Study 1 : interpreting behavior in an explanatory vacuum}

In this study, we tested whether individuals in an explanatory vacuum would use accessible goal information to interpret their norm-violating behavior and thereby alleviate negative affect. Two explanatory vacuum conditions were created by nonconsciously activating a competitive goal in a cooperative context (the two explanatory vacuum conditions differed only in whether the conscious goal that preceded this norm-violating goal could be used to explain their competitive behavior); the other groups either had a norm-conforming goal (i.e., to be cooperative in a cooperative context) or set their competitive or cooperative goal consciously. In line with Kay and Ross (2003), we used the task's name to explicitly express a cooperative situational norm. The competitive goal in this cooperative context caused participants to act quickly in order to beat their partner. In one explanatory vacuum condition, an earlier goal to be fast in a different task could be used to explain their competitive (i.e., fast) behavior, whereas in the other explanatory vacuum condition, an earlier goal to be accurate could not (i.e., it was inapplicable). This earlier goal was accessible, because it was consciously activated and just preceded the game in the second task. We hypothesized that only individuals whose earlier accessible goal was to be accurate (i.e., a goal that could not explain their norm-violating behavior) would experience the negative affect typically associated with an explanatory vacuum.

\section{Method}

\section{Participants and design}

One hundred and thirty-one undergraduates volunteered to participate for partial course credit. Participants were randomly assigned to condition in a 2 (first goal: fast vs. accurate) $\times 2$ (second goal content: cooperate vs. compete) $\times 2$ (second goal type: conscious vs. nonconscious) design.

\section{Procedure}

Participants signed consent forms and were told they would be completing two separate tasks that would take about one hour. No cover story was given in order to keep participants unsure about the connection between the different components.

First goal and the verb generation task. For the first task, participants completed a verb generation task. Participants were presented with 52 nouns (e.g., thief, dog) and were asked to write a prototypical verb for each noun (e.g., steal, bark). The instructions implied that there were both right and wrong answers, as "a prototypical verb is a word depicting an action that is most related to the central meaning of the noun." Participants were either given the conscious goal to be accurate or fast in this verb generation task, and were told that they would have two minutes to complete the task. The number of verbs generated in these 2 min was used as a manipulation check for the first goal.

Second goal. Before the second task, participants were either consciously or nonconsciously (i.e., subliminally) given the goal to cooperate or compete. Those in the nonconscious goal conditions were presented with goal-related words as part of a "reaction-time measure." Those in the nonconscious competition goal condition saw words related to a competition goal (i.e., compete, win, beat, conquer), whereas those in the nonconscious cooperation goal condition saw words related to a cooperation goal (i.e., cooperate, help, assist, share). Those in the conscious goal conditions (see below) saw unrelated words during this reaction-time measure (i.e., plant, car, lamp, building). The four words were presented 20 times each for $17 \mathrm{~ms}$ in one of four randomly-selected parafoveal regions on the screen; each subliminal presentation was backwardmasked by a nonsense letter string (Bargh \& Chartrand, 2000; Kawada, Oettingen, Gollwitzer, \& Bargh, 2004). Participants were asked to respond to whether the "flash of letters" appeared on the right or left side of the screen.

Individuals in the conscious competition goal or conscious cooperation goal condition then read a goal intention derived from three of the words used in the nonconscious goal conditions. Those in the conscious competitive goal condition read, "In this task, please form the goal to compete strongly against the other participant. Your goal should be to beat the other participant in order to clearly win the task." Those in the cooperative goal condition read, "In this task, please form the goal to cooperate strongly with the other participant. Your goal should be to assist the other participant in order to clearly share the success in the task."

Search task. In the second task, participants worked with a "partner" (ostensibly another participant communicating through networked computers) to find sets of three numbers in a complex matrix of letters and numbers adding up to 5, 15, or 25. Above this matrix was displayed the title: "The Cooperative Where's Waldo Game." Participants identified the number sets by entering the two letters that appeared on either end of the number set. Participants received a point for each set of numbers they entered, and they were asked to monitor their own points as well as their partner's points (which were pre-programmed to appear slowly, at one third the pace of pilot participants). They were told to stop working on the task and to alert the experimenter when their combined points reached 30 . Thus, in this task, acting competitively required acting quickly, whereas acting cooperatively required acting slowly to allow the other participant gain more points.

Reflective questions. A number of exploratory questions were included to assess participants' interpretation of their behavior. Participants were asked to select what goal they were trying to achieve (out of four choices) and to rate on a scale from 1 to 7 to what extent they were trying to be fast, accurate, competitive, or nice in the search task.

Negative affect measures Lastly, participants completed five selfreport items measuring negative affect, rated on a scale from 1 to 7. These items were combined into a Negative Affect scale $(\alpha=.82)$ including guilty, upset, ashamed, uneasy, and anxious.

Results

Manipulation check: verb generation task

The effect of the first conscious goal to be fast or accurate on verb generation speed was checked in the verb generation task. In the two minutes provided, participants with a conscious goal to be fast generated more verbs $(M=30.40, S D=8.34$ ) than those with a conscious goal to be accurate $(M=25.77, S D=8.80)$, $t(129)=3.10, p=.002$, indicating that the first goal impacted speed on the verb generation task as expected.

Manipulation check: search task

The effect of the second conscious or nonconscious goal to be competitive or cooperative was analyzed using a 2 (first goal: fast 
vs. accurate) $\times 2$ (goal content: compete vs. cooperate) $\times 2$ (goal type: conscious vs. nonconscious) ANOVA. As expected, only the main effect of the second goal content had a significant impact on the number of points scored in the search task, $F(1,123)=3.98$, $p<.05$. Participants with the goal to compete (conscious: $M=21.85, S D=2.32 ;$ nonconscious: $M=21.94, S D=2.82$ ) scored more points than those with the goal to cooperate (conscious: $M=21.35, S D=1.70$; nonconscious: $M=20.97, S D=1.66$ ), with no interaction between goal content and goal type (i.e, conscious vs. nonconscious), $F<1$, indicating that the second goal impacted performance on the search task as expected.

In addition, this manipulation check confirmed that the first goal did not affect performance in the later search task, with participants with an earlier conscious goal to be fast $(M=21.78$, $S D=2.45)$ not differing significantly from those with an earlier goal to be accurate $(M=21.28, S D=1.86), F(1,123)=1.80, p>.18$. No other effects neared significance (all ps $>.22$ ).

\section{Exploratory measures: reflective questions}

The exploratory measures regarding the nonconscious goal participants' interpretation of their goals and performance revealed no reliable pattern. When asked to select what goal explained their behavior, participants did not differ based on their earlier conscious goal $\left(\chi^{2}=1.98, p>.57\right)$. Participants in the nonconscious goal conditions did not differ in the extent to which they reported they were trying to be fast (all $p s>18$ ), accurate (all $p s>.60$ ), competitive (all $p s>.35$ ), or nice (all $p s>.50$ ). Participants appeared unable to consciously report on their explanation of the goals driving their behavior.

\section{Dependent variable: negative affect ratings}

A 2 (first goal: fast vs. accurate) $\times 2$ (goal content: compete vs. cooperate) $\times 2$ (goal type: conscious vs. nonconscious) ANOVA on the Negative Affect scale revealed a marginal 3-way interaction, $F(1,123)=2.40, p=.12$, and a significant main effect of first goal content on negative affect, $F(1,123)=4.47, p<.05$, entirely driven by the heightened negative affect of participants with a earlier accuracy goal and a later nonconscious goal to compete (the explanatory vacuum condition without an applicable explanation). To ensure that the effects of the first goal (i.e., speed vs. accuracy) was not responsible for the observed pattern of affect ratings, performance in the first task was entered as a covariate in the model; it did not have a significant impact on affect ratings, $F<1$. A planned contrast was subsequently conducted to directly test our prediction that only those in the explanatory vacuum condition (i.e., with a nonconscious goal to compete) whose earlier goal could not explain this behavior (i.e., with a first goal to be accurate) would show an increase in negative affect. The following weights were applied to the contrast: lambda $=-1,7,-1,-1,-1,-1,-1,-1$ for the nonconscious compete goal with an earlier speed goal, nonconscious compete goal with an earlier accuracy goal, nonconscious cooperate goal with an earlier speed goal, nonconscious cooperate goal with an earlier accuracy goal, conscious compete goal with an earlier speed goal, conscious compete goal with an earlier accuracy goal, conscious cooperate goal with an earlier speed goal, and conscious cooperate goal with an earlier accuracy goal, respectively. This contrast revealed a highly significant difference between the negative affect of those with a nonconscious compete goal with an earlier accuracy goal $(M=2.35, S D=1.46)$ compared to the rest of the conditions $(M S=1.40-1.82, S D S=.48-1.22), t(123)=3.17, p=.002$. See Fig. 1. Repeating this planned contrast on the residual after controlling for performance on the first task showed that this one condition still differed significantly from the others, $f(123)=3.11, p=.002$, suggesting again that the first goal only impacted affect through at tribution processes.

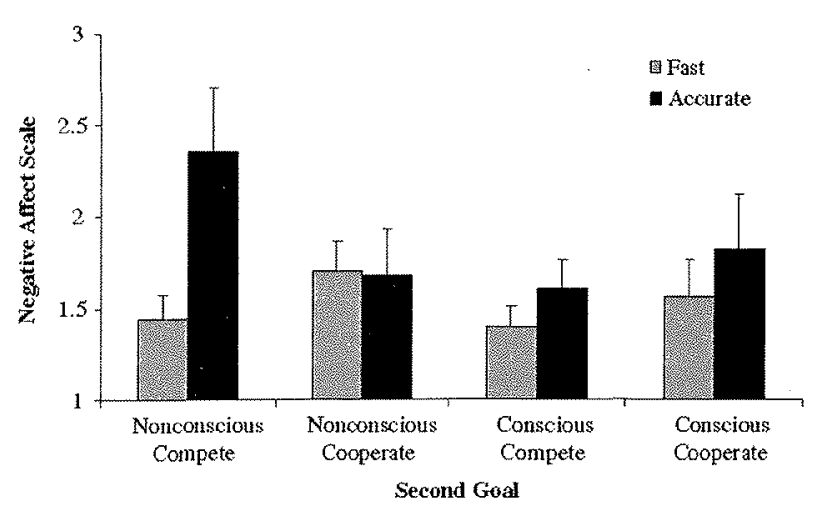

Fig. 1. Mean Negative Affect scale ( $+5 E$ ) in Study 1 as a function of first goal and second goal conterit and type.

To ensure that this main effect of first goal content on negative affect was entirely driven by the heightened negative affect of the explanatory vacuum participants who could not explain their behavior as expected, and not merely a main effect of having an accuracy goal, two further analyses were conducted. First, among those with an earlier goal to be accurate, we expected that only those in the explanatory vacuum condition (i.e., with a later nonconscious goal to compete) would show an increase in negative affect. Thus, the following weights were applied to build a contrast comparing those with an earlier accuracy goal only: lambda $=3$, $-1,-1,-1$, to compare accuracy participants with a nonconscious compete second goal to participants with nonconscious cooperate second goal, a conscious compete second goal, and a conscious cooperate second goal, respectively. This contrast was highly significant, $f(123)=2.55, p=.01$.

Second, without the explanatory vacuum participants who could not explain their behavior (i.e., those with an earlier accuracy goal), we did not expect a difference in negative affect between those with an earlier goal to be fast or accurate. When the ANOVA was conducted without this one condition (i.e., nonconscious compete goal with an earlier accuracy goal), no main effect of first goal content remained, $F<1$. These two additional analyses fully supported our hypothesis that only participants who found themselves in an explanatory vacuum experienced heightened negative affect when this could not be explained by their earlier conscious goal (in this case, an accuracy goal).

In a most direct test of our hypothesis, we expected that participants in an explanatory vacuum who could potentially explain their norm-violating behavior using an earlier applicable goal would spontaneously interpret their behavior, thereby eliminating the negative affect associated with an explanatory vacuum. A t-test comparing the two explanatory vacuum conditions (i.e., those with a nonconscious goal to compete in the second task) confirmed that negative affect was significantly lower in those whose earlier goal to be fast explained their competitive behavior $(M=1.44, S D=.52)$ compared to those whose earlier goal to be accurate could not explain their competitive behavior $(M=2.35, S D=1.46), t(30)=2.29$, $p<.03$. The negative affect of participants in the other goal conditions (i.e., those with a nonconscious cooperative goal, a conscious competitive goal, and a conscious cooperative goal in the second task) did not differ based on the content of their earlier goal (all $p s>$.29).

\section{Discussion}

Study 1 replicates the Oettingen et al. (2006) finding that an explanatory vacuum is associated with heightened negative affect. 
with one important addition: participants who were able to misattribute their norm-violating behavior to an earlier conscious speed goal showed a significant reduction in this negative affect as compared to those with an earlier inapplicable accuracy goal. Participants were not able to verbally express the interpretation that reduced their negative affect (i.e, they were no more likely to say they were trying to be fast in the task); instead it seemed to occur reflexively. That this interpretation was indeed a misattribution is supported by manipulation checks confirming that the first goal did not affect performance in the second task. Supporting our predictions, individuals who pursued nonconsciously-activated norm-violating goals spontaneously interpreted their behavior in line with an earlier applicable goal, thereby protecting the self from aversive negative affect.

The present study may remind the reader of work by Zanna and Cooper demonstrating that the use of dissonance reduction strategies is reduced if participants are able to misattribute their discomfort to an alternative source (Fazio, Zanna, \& Cooper, 1977; Zanna \& Cooper, 1974). For example, Zanna and Cooper (1974) found that when participants were told a pill would make them feel tense, they did not show the typical dissonance effect in which high choice subjects change their attitudes more than low choice subjects. In that case, participants' discomfort was misattributed to a pill ostensibly responsible for their feelings, whereas in the present study, participants" goal-directed behavior was misattributed to an earlier goal potentially responsible for their norm-violating behavior.

It is interesting that the exploratory measures revealed no meaningful pattern, as this further suggests that interpretive processes occur outside of awareness. However, the presence of these questions in our design leads us to an important issue: is experimentally-induced self-reflective thought a necessary condition for behavior in an explanatory vacuum to be interpreted? A second study was conducted to explore this possibility, in which participants in an explanatory vacuum were given time to reflect on their behavior and the cause of their behavior (reflection condition), or were asked about their negative affect directly following the search task (no-reflection condition).

\section{Study 2: does interpreting nonconscious goal pursuit require reflection?}

A second study was undertaken to both replicate the findings from Study 1 and to examine whether interpreting behavior in an explanatory vacuum requires prompted conscious reflection on the goals underlying one's behavior. In Study 1, participants were asked to respond to exploratory questions about the purpose of their behavior before reporting on their negative affect. In the confabulation literature, there is a distinction made between those formed automatically-spontaneous confabulations-and those given in response to a question by an authority figure, known as provoked confabulations (Kopelman, 1987). These terms reflect the distinction we would like to examine between reflexive, nonintentional interpretation, and reflective, deliberative interpretation initiated in response to a question by the experimenter.

In line with Cooney and Gazzaniga's suggestion that the interpretive system serves to "reflexively formulate causal theories about why events occur" (2003, p. 162), we predicted that participants would reflexively interpret their norm-violating behavior in line with their earlier applicable goal. However, the design in Study 1 leaves open a reflective process, with participants forming a coherent story to explain their behavior in response to the prompting questions posed by the experimenter. This issue is examined in Study 2 by either providing an opportunity for reflection or not. To focus on the cells of interest, only the explanatory vacuum condi- tions (in which a norm-violating goal is activated nonconsciously) from Study 1 were included. Because we propose conscious reflection is not necessary for interpreting nonconscious goal pursuit, we predicted a single main effect of first goal content on negative affect.

\section{Method}

\section{Participants and design}

Eighty-six undergraduates volunteered to participate for partial course credit. Participants were told they would be completing two separate tasks and that the study would take one hour. All participants were placed in an explanatory vacuum in the second task (i.e., a competition goal was nonconsciously activated in a cooperative context). Participants were randomly assigned to conditions in a 2 (first goal: fast vs. accurate) $\times 2$ (post-task instructions: reflection $v s$. no reflection) design.

\section{Procedure}

First goal and verb generation task. Participants were explicitly given the goal to be fast or accurate on a verb generation task as described in Study 1. The number of verbs generated in response to the provided nouns in 2 min was used as a manipulation check for the first goal.

Second goal. Before the second task, all participants were subliminally presented with competition goal-related words (e.g., compete, win, beat, conquer) as part of a "reaction-time measure" as in Study 1 . Thus, all participants were placed in an explanatory vacuum, as they were nonconsciously primed with the goal to act competitively in a cooperative task.

Search task. Participants then completed the second task, prominently labeled "The Cooperative Where's Waldo Game" to install a cooperative norm (Kay \& Ross, 2003). As in Study 1, participants believed they were working with a partner over networked computers to find sets of three numbers in a complex matrix of letters and numbers adding up to 5,15 , or 25. Participants again received a point for each set of numbers they entered, and they were asked to monitor their own points as well as their partner's points. In the present study, participants were told to stop working on the task and to alert the experimenter when the combined points reached $20 .^{2} \mathrm{Again}$, acting competitively was synonymous with acting quickly in this task.

Post-task instructions. Experimenter-prompted reflection was manipulated through the inclusion or exclusion of questions concerning the participants' goals and performance in the search task. First, participants in the reflection condition were asked to write a few sentences explaining what their goal was in the task (besides the given task goal of finding the stimuli), and what they were thinking about during this task. Participants were also asked to report on how well they performed, as well as how fast, accurate competitive, and nice they were on the search task. Those in the no-reflection condition proceeded immediately to the affect measures following the search task.

Negative affect measures. Participants then reported on their negative affect. We replaced "uneasy" from Study 1 with "nervous," resulting in a Negative Affect scale $(\alpha=.73)$ including guilty, upset, ashamed, nervous, and anxious.

\footnotetext{
${ }^{2}$ The number of combined points was reduced from 30 to 20 merely to reduce the time required of participants to finish the study; it took approximately $45 \mathrm{~min}$ to complete.
} 
Results

Manipulation check: verb generation task

The effect of the first conscious goal to be fast or accurate was checked by examining performance in the verb generation task. Participants with a conscious goal to be fast generated more verbs $(M=34.82, S D=8.87)$ than those with a conscious goal to be accurate $(M=25.39, S D=8.24),(84)=5.09, p<.001$, indicating that the first goal impacted speed on the first task as expected.

\section{Manipulation check: search task}

To ensure that the first goal did not affect behavior in the second task, the effect of the first conscious goal on points scored in the search task was examined. Participants with an earlier conscious goal to be fast did not score significantly more points $(M=15.07, S D=1.29)$ than those with an earlier conscious goal to be accurate $(M=14.54, S D=2.54), n(84)=1.24, p=.22$. Participants were asked to stop when they reached 20 combined points; on average they scored 14.81 points $(S D=1.99)$.

\section{Dependent variable: negative affect ratings}

A 2 (first goal: fast vs. accurate) $\times 2$ (post-task instructions: reflection vs. no reflection) ANOVA on the negative affect scale revealed a significant main effect of first goal on negative affect $F(1,82)=4.25, p<.05$, with no main effect of reflection $(p>.45)$ or interaction effect $(p>45)$. Whether participants with an earlier goal to be fast were prompted to reflect on their goals and performance $(M=1.50, S D=.74)$ or did not $(M=1.50, S D=.51)$, they showed a lower level of negative affect than those with an earlier inapplicable accuracy goal whether they did have a chance to reflect on their goals and performance $(M=1.72, S D=.86)$ or did not $(M=1.97, S D=.95)$. A follow-up t-test confirmed that among participants who were not able to reflect on their goals and performance (i.e., the no-reflection condition), negative affect significantly differed between the two first goal conditions, $\mathrm{t}(42)=2.08$, $p<.05$ (see Fig. 2). This suggests that interpretation in an explanatory vacuum does not require conscious self-reflective thought.

\section{Other findings}

The open-ended responses in the reflection condition were content-coded for competition and speed-related goals. The proportion of individuals with an earlier goal to be fast who mentioned speed-related goals (19.05\%) did not differ from those with an earlier goal to be accurate $(33.33 \%), \chi^{2}=1.11, p=.29$. In addition, the proportion of participants with an earlier goal to be fast who mentioned competition-related goals $(38.10 \%)$ did not differ from those

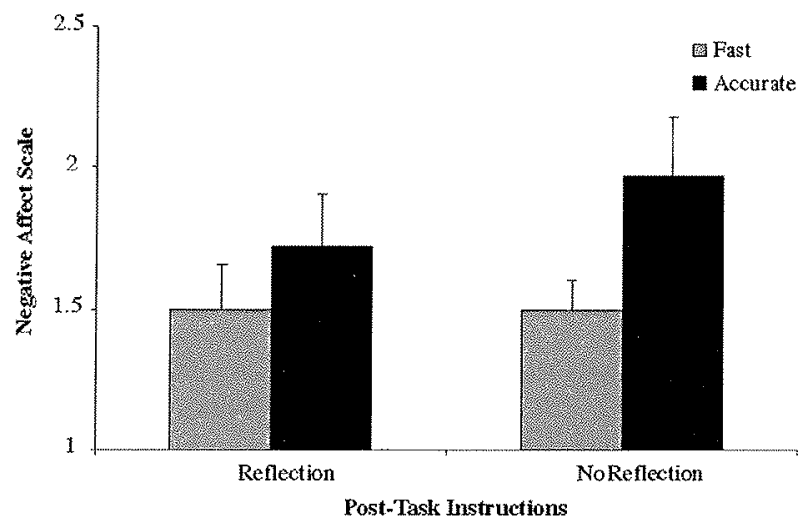

Fig. 2. Mean Negative Affect scale ( $+S E$ ) in Study 2 as a function of first goal and post-task instructions. with an earlier goal to be accurate $(23.81 \%), \chi^{2}=1.00, p=.32$. None of the self-ratings of performance differed between the two first conscious goal conditions ( $p s>34$ ).

\section{Discussion}

Whether or not participants were given time to reflect on their goals and performance in the search task, the accessibility of an earlier applicable goal led to significantly lower self-reported negative affect than when the earlier conscious goal was inapplicable to competitive behavior. This suggests that alleviating the negative affect associated with an explanatory vacuum by interpreting behavior in terms of an earlier applicable goal does not require experimenter-prompted conscious reflection about one's goals and intentions. Rather, individuals who are highly motivated to explain their behavior (i.e., when it is norm-violating) appear to spontaneously interpret their goal-directed behavior using applicable goals. In addition to not being prompted by the experimenter to reflect, those in the no-reflection condition were not given enough time to self-initiate reflection about their performance. Thus those in the no-reflection condition did have less time in between the search task and negative affect ratings, a potential confound This short lapse of time was enforced however to ensure that participants in this no-reflection condition did not have the opportunity to consciously reflect on their behavior.

Although an explanatory vacuum does appear to motivate explanatory processes, not all individuals are equally motivated to find consistency in their behavior. In Study 3, we included an individual difference measure designed to capture these differences in participants' preference to find consistency in their behavior, which we expected to interact with the presence of an earlier applicable goal. The Preference for Consistency scale (PFC; Ciadini, Trost, \& Newsom, 1995) identifies individual differences in the extent to which people prefer to find consistency in their behavior with their past goals and beliefs. We expected that the more our participants are motivated to find consistency in their own behavior, the more they would use the earlier goal (if applicable) to interpret their behavior in the second task.

We also included a second individual difference expected not to interact with the applicability of an earlier accessible goal. Based on the findings in Study 2 suggesting that interpretation does not require conscious reflection, but is reflexive, we expected the Need for Cognition (NFC; Cacioppo \& Petty, 1982) would not interact with the applicability of the earlier accessible goal. Interpretation of behavior in an explanatory vacuum should be independent of NFC.

In addition to these individual difference measures, we predicted that the interpretation of nonconscious goal striving would impact actual interpersonal behavior. Rather than focus again on self-reported negative affect, we were interested in the effects of interpretation on helping behavior in terms of lottery tickets shared with one's partner. Past research has demonstrated that transgressions lead to increased helping behavior in order to alleviate negative affect (Manucia, Baumann, \& Cialdini, 1984; Schaller \& Cialdini, 1988), this helping is in proportion to their feelings of guilt (Baumeister, Stillwell, \& Heatherton, 1994; Berscheid \& Walster, 1967), and feelings of guilt produced from transgressing against one individual lead to greater cooperation in later interactions with that same individual (Ketelaar \& Au, 2003). Because participants' primed competitive behavior harms their ostensible partner, greater subsequent cooperation and sharing with that partner would be expected as a means of alleviating the guilt and negative affect associated with behaving in an explanatory vacuum.

However, in the present study negative affect should only motivate prosocial behavior towards one's partner when the 
norm-violating behavior cannot be interpreted some other way. Cialdini and colleagues found that when negative mood could be repaired before the opportunity for helping arose, participants were no more helpful than control subjects (Cialdini, Darby, \& Vincent, 1973). Moreover, we predicted that Preference for Consistency (PFC) would be associated with greater sharing when participants first had an accuracy goal, as they would be motivated to reduce this negative affect. However, we expected that PFC would be associated with less sharing when participants first had a speed goal, which could be used to explain their competitive behavior and would thereby eliminate the motivation to help one's partner.

\section{Study 3: individual differences and interpersonal behavior}

In Study 3, we examined the impact of individual differences and accessible goal applicability on interpersonal behavior in a modified dictator game (Camerer \& Thaler, 1995; Kirk, Gollwitzer, Carnevale, \& McMeniman, submitted for publication). Specifically, because the norm-violating goal (to compete in a cooperative task) was acted out at a cost to the supposed partner, we expected that the inability to explain away this competitive behavior (i.e., in the accuracy goal condition) would be associated with increased lottery ticket sharing with one's partner as Preference for Consistency (PFC) scores increased. Conversely, because an earlier speed goal could allow reflexive interpretation of norm-violating behavior, thereby eliminating any aversive negative affect, the accessibility of an applicable goal (in the speed goal condition) should be associated with less sharing with one's partner as PFC scores increased. On the other hand, we expected that NFC would not interact with goal applicability to predict cooperative behavior, as we predict interpretation is a reflexive, rather than reflective, process.

The variable of interest in this third study was sharing behavior, and for this reason we excluded self-report affect measures preceding this behavioral measure. Self-report measures can affect later behavior and judgments in multiple ways; reporting negative affect may draw participants' attention to their current feelings and thereby lead them to subtract their influence on their later behaviors and judgments (e.g., Schwarz \& Clore, 1983). Admitting negative emotions (e.g., guilt) can also relieve the pressure to alleviate them through altruistic behavior (e.g., as confession reduces men's charitable donations; Harris, Benson, \& Hall, 1975). In the following study, we examined the impact of individual differences and earlier applicable goals on cooperative behavior following norm-violating behavior in an explanatory vacuum.

\section{Method}

\section{Participants and design}

One hundred undergraduates volunteered to participate for partial course credit. The procedure followed Study 2, with the addition of two individual difference questionnaires and an adapted dictator game replacing negative affect as the dependent variable. After completing the initial questionnaires, participants were randomly assigned to one of two conditions (first goal: fast vs. accurate); all participants were then placed in an explanatory vacuum in the second task (i.e., a competition goal was nonconsciously activated in a cooperative context).

\section{Procedure}

Participants first completed the Preference for ConsistencyBrief Scale (PFC-B, Ciadini et al., 1995) and the 18-item Need for Cognition Scale (NFC, Cacioppo, Petty, \& Kao, 1984). Participants then received a conscious goal to be fast or accurate on a verb generation task, copied this goal down on the page, and completed the verb generation task as described in Study 1. Participants then completed the competitive goal priming procedure and cooperative search task as described in Study 2 . No reflection questions or negative affect measures were included.

Dictator game. Immediately following the search task, participants were given an envelope, 10 lottery tickets, and a form instructing them to divide the 10 lottery tickets between themselves and their partner from the cooperative search task. Past research has shown that lotteries are as viable as a financial motivator in bargaining games as money (Robert \& Carnevale, 1997; Roth \& Malouf, 1979). This form explained, "You can give your partner as many (all 10) or as few $(0)$ of the tickets as you would like. There are real consequences for your decision-the more lottery tickets a person has, the higher his/her chances of winning one of two $\$ 50$ cash prizes." Participants were told they would be contacted by email if they won. Participants were then asked to place the tickets (if any) for the partner in the envelope, to write their email address on the remaining tickets for themselves, and to place these tickets in a box that was visible from the start of the experiment with the sign "Lottery Tickets. Prizes: Two $\$ 50$ Winners."

Lastly, participants were asked to rate their partner's effort $(\alpha=.94)$ and their own effort $(\alpha=.90)$ in terms of how much they: cared about their performance, took the tasks seriously, and put forth a serious effort. The partner's perceived effort was subtracted from the self-reported effort to form a difference in perceived effort scale $(\alpha=.94)$

\section{Results}

\section{Manipulation check: verb generation task}

The effect of the first conscious goal to be fast or accurate was checked by examining speed in the verb generation task. Participants with a conscious goal to be fast generated more verbs in two minutes $(M=30.34, S D=5.63)$ than those with a conscious goal to be accurate $(M=21.46, S D=6.25), t(98)=7.47, p<.001$, indicating that the first goal successfully impacted speed in the verb generation task as intended.

\section{Manipulation check: search task}

To ensure that the first goal did not affect competitive behavior in the search task, the effect of the first conscious goal on points scored was examined. Participants with an earlier conscious goal to be fast did not score significantly more points $(M=14.72$, $S D=1.57$ ) than those with an earlier conscious goal to be accurate $(M=14.48, S D=1.53), t(98)=.78, p=.44$. Out of 20 combined points with their computerized partner, participants averaged 14.60 points $(S D=2.16)$.

\section{Manipulation check: partner and self ratings}

To ensure that differences in perceived ability or effort did not account for the differences in cooperative behavior in the dictator game, we analyzed the partner and self ratings. Paired $t$-tests confirmed that participants did rate themselves as having cared more about their performance, $t(97)=12.47, p<.001$, taken the task more seriously, $t(97)=11.68, p<.001$, and put forth more of a serious effort, $t(97)=13.25, p<.001$, than their ostensible partner. The average difference in perceived effort was $2.40(S D=1.80)$, which differed significantly from zero, $t(97)=13.21, p<.001$. In sum, participants indicated that they had put forth significantly more effort into the search task than their partner.

\section{Dependent variable: shared lottery tickets}

The number of lottery tickets shared with the supposed partner was subjected to a linear regression. The modal response for tickets 
shared was $5(N=27)$, with the second most common response of 0 $(N=22 ; M=3.07, S D=2.16)$.

The number of tickets shared with the partner was first regressed on goal condition, NFC, PFC, with the interaction between goal condition and NFC entered in a second step, and the interaction between goal condition and PFC entered in a third step. As expected, only the interaction between goal condition and PFC significantly predicted tickets shared $(\beta=.39) t(96)=2.34, p=.02$. Adding the interaction of goal condition and NFC in the second step did not result in a significant $R$-square change, $F(1,95)=.81$, $p>35$, but adding the interaction of goal condition and PFC in the third step did result in a significant $R$-square change, $F(1,94)=5.46, p=.02$. Separate regression analyses were then conducted for PFC and NFC, respectively.

Preference for Consistency. The number of tickets shared with the partner was regressed on conscious goal condition and PFC score, with the interaction between these terms added as a second step. As predicted, the only significant finding was an interaction between goal condition and $\operatorname{PFC}(\beta=.38) t(96)=2.25, p<.03$ (see Fig. 3). Adding the interaction term resulted in a significant $R$ square change, $F(1,96)=5.06, p<.03$. No other predictors were significant ( $p s>.50$ ). A simple slopes analysis revealed that the difference between the slopes presented in Fig. 3 was significant $(\beta=.76) t(96)=2.25, p<.03$

In order to ensure that differences in perceived effort between the participant and partner could not account for differences in shared tickets, the mean difference in perceived effort scale was included. The scale significantly predicted tickets shared $(\beta=-.40)$ $t(93)=3.38, p=.001$, but did not reduce the significance of the interaction. Controlling for mean difference in perceived effort, the interaction between goal condition and PFC remained significant $(\beta=.40) t(93)=2.49, p=.01$, indicating that increases in PFC were associated with reductions in tickets shared when the earlier goal to be fast could explain their competitive behavior, but associated with increases in tickets shared among those with an earlier inapplicable accuracy goal who could not explain their competitive behavior.

The explanatory vacuum notion implies that participants high in PFC with an applicable earlier goal (i.e., to be fast) will be particularly unmotivated to share lottery tickets with their partner. In order to test this hypothesis, a median split of PFC scores was used to create high PFC and low PFC groups. We then conducted a planned contrast with the following weights: lambda $=1,1,1,-3$ for the low PFC participants with an earlier goal to be accurate $(M=3.15, S D=2.27)$, low PFC participants with an earlier goal to be fast $(M=3.67, S D=2.33$ ), high PFC participants with an earlier

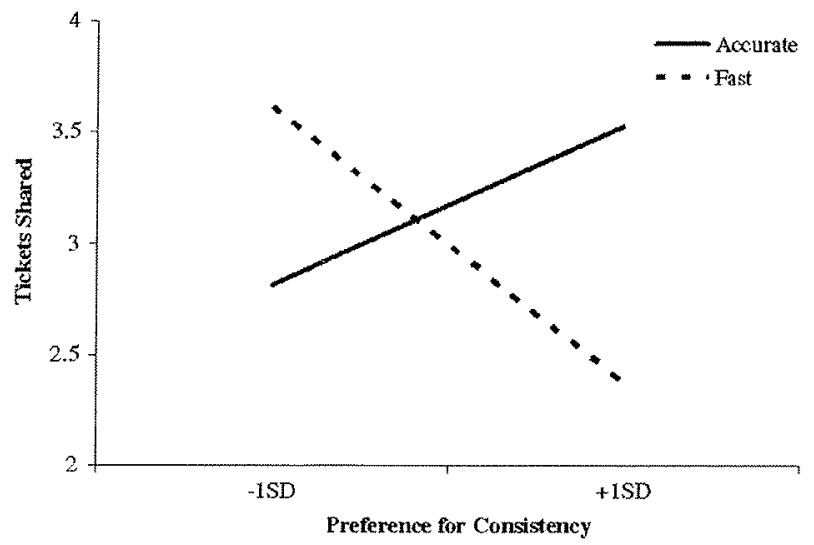

Fig. 3. Tickets shared as a function of conscious goal condition and Preference for Consistency. Means are platted $₫ 1$ SD from the mean. goal to be accurate $(M=3.17, S D=1.77)$, and high PFC participants with an earlier goal to be fast $(M=2.35, S D=2.12)$, respectively. This contrast was significant, $t(96)=2.01, p<.05$. Follow-up $t$-tests revealed that high PFC participants with an earlier goal to be fast shared significantly less lottery tickets than participants in the two accuracy goal conditions, $t(96)=2.05, p<.05$, whereas low PFC participants with an earlier goal to be fast did not differ from the two accuracy conditions, $t(96)=.53, p=.60$.

Need for Cognition. A separate regression was then conducted regressing the number of tickets shared on conscious goal condition and NFC score. NFC marginally predicted tickets shared across both goal conditions $(\beta=.64) t(96)=1.74, p<.09$, but as predicted, the interaction between goal condition and NFC was not significant $(p>.40)$, suggesting that effortful cognition is not related to interpretation in an explanatory vacuum. Controlling for mean differences in perceived effort revealed a significant main effect of NFC $(\beta=.72) t(93)=2.02, p<.05$, signifying that those higher in NFC shared more tickets with their partner, but as predicted, the interaction remained insignificant $(p>.50)$, indicating that the ability to interpret their behavior did not interact with NFC.

\section{Discussion}

Preference for Consistency (PFC), indicative of participants' preference to find consistency with past behavior, positively predicted the number of tickets shared in a dictator game when norm-violating competitive behavior could not be interpreted using an earlier conscious goal. However, the opposite association was found between PFC and tickets shared when participants were given an earlier goal to be fast, which could be used to explain competitive behavior. When participants were given an applicable speed goal on an earlier task, PFC was associated with a reduction in the number of tickets shared. This suggests that the more participants expect themselves to be consistent with their past goals, the less driven individuals are to engage in cooperative interpersonal behavior when an earlier goal can explain their antisocial behavior.

Need for Cognition (NFC), on the other hand, did not interact with the applicability of accessible goals. This provides further evidence that the interpretation of nonconscious goal pursuit is not a reflective process, but a reflexive one. NFC was marginally associated with sharing behavior, in that NFC was positively associated with tickets shared with one's partner, regardless of the applicability of the earlier conscious goal.

\section{General discussion}

In three studies, we examined the interpretation of nonconscious goal striving by assessing negative affect and interpersonal behavior. We found that participants used earlier conscious goals to interpret their otherwise inexplicable behavior, and that when applicable, accessible goals mitigated the negative affect typically associated with acting in an explanatory vacuum. In Study 1, an earlier accessible goal with congruent behavior effects eliminated the negative affect associated with nonconsciously-activated norm-violating behavior. Study 2 provided evidence that the interpretation of behavior in an explanatory vacuum occurred reflexively, rather than through reflection, and without conscious awareness of the interpretive process. In Study 3, we examined how the interpretation of nonconscious goal pursuit could affect helping behavior, as norm-violating behavior should only motivate helping one's partner when the negative affect could not be repaired through interpretation. We found that Preference for Consistency (PFC) was negatively associated with tickets shared when participants first had a conscious goal to be fast, which had 
congruent behavioral effects, and could therefore explain the norm-violating behavior. The more participants were able to explain their negative affect through their earlier goal, the less tickets they shared with their partner. Further, the argument that interpretation occurs reflexively was bolstered by evidence in Study 3 that Need for Cognition (NFC) did not interact with the applicability of accessible goals to affect tickets shared with the partner. Together, these three studies provide evidence that individuals in an explanatory vacuum use accessible goal information readily and extensively to explain their norm-violating behavior, settling for explanations that merely suffice.

The current research makes use of diverse methods to extend the explanatory vacuum theory (Oettingen et al., 2006). Studies 1 and 2 directly measure negative affect through self-report, whereas Study 3 addresses the criticism of Baumeister, Vohs, and Funder (2007) (i.e., that self-reports are often inaccurate and complementary behavioral measures are therefore valuable) by measuring the number of tickets shared with one's partner in an actual lottery as a behavioral consequence of interpretation in an explanatory vacuum. The reflexive vs, reflective nature of interpretation is examined both by manipulating the opportunity for reflection in Study 2 and through an individual difference measure in Study 3. Lastly, the use of earlier applicable goals is examined by both manipulating the goals' applicability and through an individual difference measure that reflects participants' preference to find consistency in their own behavior in Study 3. These personality and manipulated independent variables, as well as the self-report and behavioral dependent variables, combine to support our thesis that behavior in an explanatory vacuum is reflexively interpreted using accessible applicable goals.

\section{Implications}

This research examines a little explored question: how do individuals go about interpreting goal-directed behavior that has been nonconsciously primed? That goal-directed behavior can be activated by incidental information has been shown again and again, but the current research takes a first step in examining how this nonconsciously-activated goal-directed behavior is understood as coherent by the actor. These findings suggest that norm-violating behaviors are explained through earlier applicable goal information, especially among those high in Preference for Consistency. The interpretive process also occurs spontaneously, and outside of awareness.

The idea that causation can be effortlessly misattributed to one's earlier goals should not be surprising to social psychologists. Introspection is notoriously faulty, and explanations of behavior often appear to derive from post hoc causal theories similar to what would be expected from an outside observer (Nisbett \& Wilson, 1977). Recent research on vicarious agency by Wegner and colleagues has suggested that beliefs and feelings about causation are often inaccurate (e.g., Aarts, Custers, \& Wegner, 2005; Wegner, Sparrow, \& Winerman, 2004), with individuals experiencing willful control of actions that are actually outside of their control. Participants in Wegner's studies perceive the action to be a result of their own doing, essentially interpreting causation from observing their behavior. The present research creates a void in participants' knowledge of causation by nonconsciously priming norm-violating goals, and then examines their interpretation indirectly through self-reported negative affect and interpersonal behavior. We have found that individuals attribute their behavior to recent applicable goals.

The present findings also have implications for understanding when negative affect will result from striving for implicit goals. Complementing Chartrand's (1999) research, we found that individuals may experience negative affect even when their goal pur- suits have been successful; that is, when their goal-directed behaviors contradict social norms. However, we also found that this negative affect is easily mitigated, when participants were able to misattribute their behavior to a recent conscious goal. This work has implications for understanding the role of the explanatory vacuum (Oettingen et al., 2006) in daily life. Because this negative affect is so easily reduced through reflexive interpretation, nonconsciously-activated norm-violating behaviors may be much more common than previously appreciated, as these behaviors are effortlessly misattributed to applicable goals, and the negative affect is therefore not experienced. With a constant stream of applicable goals and norms to access in one's daily life, the interpretation of behavior in an explanatory vacuum should not be difficult. This suggests that experiencing negative affect following norm-violating nonconscious goal pursuit may actually be rare.

The present research also examines a separate role of negative affect in self-regulation. Negative affect appears to motivate interpretive processes when norm-violating goal-directed behavior is nonconsciously activated. Dissonance research has similarly shown that the negative affect associated with norm-violating behavior motivates active attempts at interpretation and justification. According to Stone and Cooper, "if the behavior is perceived to be discrepant from the perceived norms, then dissonance is aroused and... individuals will become motivated to justify their behavior" (2001, p. 237). Negative affect resulting from counterattitudinal behavior has been called dissonance motivation, "the psychological discomfort that motivates or 'drives' the attitude change process" (Fazio \& Cooper, 1983, p. 132). Similarly, the current research suggests that negative affect resulting from nonconsciously-activated norm-violating goals motivates reflexive interpretive processes.

\section{Limitations and future directions}

One question that remains to be answered is whether normviolating positive behaviors would also elicit negative affect in an explanatory vacuum. This needs to be tested empirically, as two opposing hypotheses could be formed from related literatures. On the one hand, uncertainty about positive events leads to heightened positive affect (Wilson, Centerbar, Kermer, \& Gilbert, 2005). This research may suggest that performing a positive norm-violating behavior activated by a nonconscious goal (e.g., sharing in a competitive game after being primed with a cooperative goal) could lead to heightened positive affect. On the other hand, people experience discomfort when there is a discrepancy between one's behavior and situational norms (e.g., in dissonance, Elliot \& Devine, 1994; Stone \& Cooper, 2001). This implies that the violation of competitive norms through cooperative behavior could lead to heightened negative affect merely because the behavior represents an unexplainable norm violation.

A limitation of the present research is that the process underlying interpretation (i.e, of negative affect motivating interpretation) is tested indirectly (i.e., through the reduction of negative affect depending on the applicability of the goal). The work of Zanna and Cooper (1974) suggests a way to examine what motivates interpretation more directly. They found that when negative affect could be misattributed to an alternative source, dissonance reduction was no longer undertaken. Similarly, future research could explore whether an alternative explanation for negative affect would subsequently reduce the need to explain norm-violating behavior. This could highlight the motivating nature of negative affect in the interpretation process.

One interesting issue that these studies raise is the accessibility of satiated goals. Research from Zeigarnik (1927), and more recently Marsh, Hicks, and Bink (1998), has shown that goals are cognitively less accessible after completion, and may even show a 
post-fulfilment inhibition compared to baseline (Förster, Liberman \&Higgins, 2005). On the other hand, conscious knowledge of the goal one has been striving for is required when it comes to evaluating what has been achieved in comparison to what one wanted to achieve (i.e., in the post-action phase; Gollwitzer, 1990; Heckhausen, 1991). Such effortful reflections pertain to the desirability and feasibility of the goal at hand, and they inform us whether further goal striving is necessary or not. Research on the model of action phases (Heckhausen \& Gollwitzer, 1987) thus suggests that one needs to distinguish between the cognitive accessibility of a past goal and the conscious awareness of past goal striving. The present research suggests that recently pursued goals-if applicable-can be recruited after satiation to explain subsequent non-normative behavior, suggesting that people do recall past goal striving and use these goals reflexively to interpret their nonconscious goal pursuit. An interesting future research question relates to the cognitive accessibility of an applicable satiated goal when a non-normative or unexpected behavior requires an explanation. Does the accessibility of such goals (e.g., measured by a lexical decision task) again increase?

A further future direction would be to examine how automatic interpretation in an explanatory vacuum actually is. According to Bargh (1994), features of automaticity include awareness, intention, efficiency, and control. In our exploratory measures in Study 1, participants did seem to be both unaware of their interpretive processes and to have engaged in interpretation unintentionally. However, future research is needed to examine these features of automaticity more directly. In Study 2, interpretation seems to occur without extra time for conscious deliberation, but the extent to which this interpretation requires minimal cognitive resources and is therefore efficient is unknown. Could an earlier goal be used to interpret behavior under high cognitive load (i.e., while one is busy with another task)? Lastly, can we control the interpretation of behavior in an explanatory vacuum? Future research could examine this question by informing participants that their earlier goal is known to have no impact on their behavior, and therefore should not be interpreted as a potential explanation. In the present studies, we can merely conclude that the process is reflexive in the sense that it is effortless (vs. effortful: Lengfelder \& Gollwitzer, 2001; Lieberman et al., 2002) and that the outcome of the process feels intuitive or unedited (vs. intentional and deliberate; Lieberman, 2009).

Finally, it would be worthwhile to examine whether the mechanisms associated with this reflexive interpretation differ from the more deliberate interpretation used to make causal inferences about others' behavior. Lieberman (2009) suggests that reflexive and reflective processes should be associated with dissociable brain mechanisms. He suggests that brain areas related to reflexive and reflective processes should be independently related to performance outcomes, and activity in areas associated with reflective processing should be associated with diminished activity in brain regions associated with reflexive processing. We would predict that the reflexive interpretation examined here should be associated with activity in different brain areas than deliberative, conscious interpretation.

\section{Conclusion}

Research on nonconscious goal pursuit typically focuses on humans as automatic actors: goal-relevant cues lead to goal-directed behaviors. At a basic level, we also seem to be automatic interpreters of our behaviors. As early as the 19th century, philosophers marveled at our ability to experience our visual input as complete (in spite of our blind spot) and our conscious life as unitary (in spite of our faulty memory and insight). The present research examines the interpretation of nonconscious goal pursuit and the automaticity of these interpretive processes, uncovering the everyday confabulations necessary for explaining nonconsciously-activated behavior.

\section{Acknowledgments}

This material is based on work supported under a National Science Foundation Graduate Research Fellowship awarded to the first author. The authors would like to thank members of the Motivation Lab for helpful comments on an earlier version of this manuscript, as well as Ashley Simpson, Anthony Brinn, Emily Hayden, and Caitlin Bowman for their research assistance.

\section{References}

Aarts, H. Custers, R., W Wegner, D. M. (2005). On the inference of personal asthorship: Enhancing experienced agency by priming information Consciousness and Cognition: An Intermational Joumal, $14,439-458$.

Aarts, H., \& Dijksterhuis, A. (2003). The silence of the library: Environment situational norm, and social behavionr. Joumal of Personality and social Psychology, 84, 18-28.

Aarts, H., Gollwitzer, P. M., \& Hassin, R. R. (2004). Goal contagion: Perceiving is for pursuing. Journal of Persondity and Social Psychology, 87, 23-37.

Atkirison, ]. W. (1957). Motivational determinants of risk-taking behavior Psychological Review, 64, 359-372.

Bargh, J. A. (1990). Auto-Motives: Preconscious determinants of social interactions In E. T. Higgins \& E. T. Sorrentino (Eds.). Handibook of motivation and cognition (Vol. 2, pp.93-130). New York: Guilford Press

Bargh, J. A. (1994). The four horsemen of automaticity: Awareness, intention efficiency, and control in social cognition. In R. S. Wyer \& T. K. Srull (Eds.), Handbook of socinl cognition (2nd ed., pp. 1-40). Hillsdale, NI: Erlbaum.

Bargh, J. A., \& Chartrand, T. L. (2000). The mind in the middle: A practical guide to priming and automaticity research. In H. T. Reis \& C. M. Judd (Eds.), Handbook of research methods in social and personality psychology (pp. 253-285). New York, NY: Cambridge University Press.

Batgh, ]. A., Gollwitzer, P. M., Lee-Chai, A, Barndollar, K., \& Troetschel, R. (200) ). The automated will: Nonconscious activation and pursuit of behavioral goals. Journal of Personality and Social Psychology, 81, 1014-1027.

Baumeister, R. F., Stillwell, A. M., Heatherton, T. F. (1994). Guilt: An interpersonal approach. Psychological Bulletin, 115, 243-267.

Baumeister, R. F., Vohs, K. D., \& Funder, D. C. (2007). Psychology as the science of self-reports and finger movements: Whatever happened to actual behavior? Perspectives on Psychological Science, 2, 396-403.

Berscheid, E. \& Walster, E. (1967). When does a harm-doer compensate a victim? Joumal of Personality and social Psychology, 6, 435-441.

Cacioppo, J. T., \& Petty, R. E. (1982). The need for cognition. Journal of Personality and Social Psychology, 42, 116-131.

Cacioppo, J. T., Petty, R. E., Kao, C. F. (1984). The efficient assessment of need for cognition. Joumal of Personality Assessment, 48, 306-307.

Camerer, C. F., \& Thaler, R. H. (1995). Anomalies: Ultimatums, dictators, and manners. Joumal of Economic Perspectives, 9, 209-219.

Chartrand, T. L. (1999). Mystery moods and perplexing performance: Consequences of succeeding and failing at a nonconscious goal. Unpublished dissertation. New York University, New York City.

Chartrand, T. L., \& Bargh, J. A. (1996). Automatic activation of impression formation and nemorization goals: Nonconscious goal priming reproduces effects of explicit task instructions. Joumal of Personality and social Psychology, 71 explicit task.

Chartrand, T. L., Batton, A. N. \& Cheng, C. M. (2007 a). Consequences of nonconscious goal activation. In 1 . Shah \& W. Gardner (Eds.), Handbook of motivation science (pp. 342-355). New York: Guilford.

Chartrand, T. L., Dalton, A. N., \& Fitzsimons, G. J. (2007b). Nonconscious relationship reaction: When significant others prime opposing goals. Joumal of Experimental Social Psychology, 43, 719-726.

Ciadini, R. B., Trost, M. R., \& Newsom, J. T. (1995). Preference for consistency: The development of a valid measure and the discovery of surprising behavioral implications. Joumal of Personality and Social Psychology. 69, 318-328.

Cialdini, R. B., Darby, B. L. \& Vincent, ]. (1973). Transgression and altruism: A case for hedonism. Joumal of Experimental Social Psychology, 9, 502-516.

Cooney, J. W. \& Gazzaniga, M. S. (2003). Neurological disorders and the structure of human consciousness. Trends in Cognitive Sciences, 7, 161-165.

Dennett, D. C. (1982). How to study human consciousness empirically or nothing comes to mind. Synthese, $53,159-180$

Ellot, A. 1. \& Devine, P. G. (1994). On the motivational nature of cognitive dissonance: Dissonance as psychological discomfort. Joumal of Personality and Social Psychology, 67, 382-394.

Fazio, R. H., \& Cooper, J. (1983). Arousal in the dissonance process. In J. Cacioppo \& R. Petty (EAls.). Social psychophysiology: A sourcebook (pp. 122-152). New York: Guilford Press. 
Fazio, R. H., Zanna, M. P., \& Cooper, J. (1977). Dissonance and self-perception: An integrative view of each theory's proper domain of application. Joumal of Experimental Social Psychology, 13,464-479.

Festinger, L. (1957). A theory of cognitive dissonance. Evanston, lL: Row, Peterson.

Fishbach, A., \& Ferguson, M. F. (2007). The goal construct in social psychology. In A. W. Kruglanski \& E. T. Higgins (Eds.). Social psychology: Handbook of basic principles (Vol. 2, pp. 537-565). New York: Guilford Press.

Fishbach, A. Friedman, R. S. \& Kruglanski, A. W. (2003). Leading us not into temptation: Momentary allurements elicit overriding goal activation. Joumal of Bersonality and Social Psychology, 84, 296-309.

Fitzsimons, G. M., \& Bargh, J. A. (2003). Thinking of you: Nonconscious pursuit of inierpersonal goals associated with relationship partners. Joumal of Personaity and social Psychology. 84, 148-164.

Förster, J., Liberman, N., \& Higgins, E. T. (2005). Accessibility from active and fulfilled goals. Joumal of Experimental Social Psychology, 41, 220-239.

Gollwitzer, P. M. (1990). Action phases and mind-sets. In R. M. Sorrentino \& E. T Higgins (Eds.). Handbook of motivation and cognition (Vol. 2, pp. 53-92). New York: Guilford Press.

Gollwitzer, P. M., \& Bargh, ]. A. (2005). Automaticity in goal pursuit. In A. Elliot \& C. Dweck (Eds.), Handbook of competence and motivation (pp. 624-646). New York: Guilford Press.

Gollwitzer, P. M. \& Moskowitz G. B. (1996) Goal effects on action and cognition. In E. T. Higgins \& A. W. Kruglanski (Eds.), Social psychology: Handbook of basic principles (pp. 361-399). New York: Guilford Press.

Harris, M. B., Benson, S. M., \& Hall, C. L. (1975). The effects on confession on altruism. Jotumal of Sociai Psychology, 96, 187-192

Heckhausen, H. (1991). Motivation and action. New York: Springer Verlag.

Heckhausen, H., \& Golwitzer, P. M. (1987). Thought contents and cognitive functioning in motivational vs. Volitional states of mind. Motivation and Emotion, 11, $101-120$.

Hirstein, W. (2005). Brain fiction: Self-deception and the riddie of confabulation. Cambridge, MA: MIT Press.

Holland, R. W., Hendriks, M., \& Aarts, H. (2005). Smells like clean spirit: Nonconscious effects of scent on cognition and behavior. Psychological Science, 16. $689-693$.

Kawada, C. L. K., Oettingen, G. Gollwitzer, P. M., \& Bargh, I. A. (2004). The projection of implicit and explicit goals. Joumal of Personality and Social Psychology, 86, $545-559$.

Kay, A. C. \& Ross, L. (2003). The perceptual push: The interplay of implicit cues and explicit situational construals on behavioral intentions in the Prisoner's Dilemma. Joumal of Experimental Social Psychology, 39, 634-643.

Kay, A. C. Wheeler, S. C. Bargh, J. A \& Ross, L (2004) Material priming: The influence of mundane physical objects on situational construal and competitive behavioral choice. Organizational Behavior and Human Decision Processes, 95. $83-96$.

Ketelaar, T., \& $\mathrm{Au}_{*}$ W. T. (2003). The effects of feelings of guilt on the behavior of uncooperative individuals in repeated social bargaining games: An affect-asinformation interpretation of the role of emotion in social interaction. Cognition and Emotion, 17, 429-453.

Kirk, D., Gollwitzer, P. M., Camevale, P. J., \& McMeniman, M. (submitted for publication). Self-regulation in ulimatum bargaining: Accepting profitable offers through goals and plans.

Kopelman, M. D. (1987). Two types of confabulation. Journal of Neurology, Neurosurgery, and Psychiatry, 50, 1482-1487.

Langer, E. J. (1989). Mindfuiness. Reading. MA: Perseus.

Lengfelder, A. \& Gollwitzer, P. M. (2001). Reflective and reflexive action control in frontal lobe patients. Neuropsychology, 15, 80-100.

Lewin, K. (1951). Field theory in social science. Selected theoretical papers. New York: Harper \& Row

Lieberman, M. D. (2009). What zombies can't do: A social cognitive neuroscience approach to the irreducibility of reflective consciousness. In ]. Evans $K$. Frankish (Eds.). In two minds: Dual process and beyond (pp. 219-316). New York, NY: Oxford University Press.
Lieberman, M. D., Gaunt, R., Gilbert, D. T., \& Trope, Y. (2002). Reflection and reflexion: A social cognitive neuroscience approach to attributional inferettce. Advances in Experimental Social Psycholog, 34, 199-249.

Lieberman, M. D., Ochsner, K N., Gilbert, D. T, \& Schacter, D. L. (2001). Do annesics exhibit cognitive dissonance reduction? The role of explicit memory and attention in attitude change. Psychological Science, 12, 135-140.

Manucia, G. K. Baumann, D. I., \& Cialdini, R. B. (1984). Mood infuences on helping: Direct effects or side effects? Joumal of Personality and Social Psychologyt 46 , 357-364.

Marsh, R. L. Hicks, J. L., \& Bink, M. L. (1998). Activation of completed, uncompleted, and partially completed intentions. Joumal of Experimental Psychology: Learning. Memory, and Cognition, 24, 350-361.

McGraw, K M. (1987). Guilt following transgression: $A r_{s}$ attribution of responsibility approach Joumat of Personality and Social Psychology. 53, 247-256.

Moskowitz, G. B., Gollwizzer, P. M., Wasel W., \& Schaal, B. (1999). Preconscious control of stereotype activation through chronic egalitarian goals. Joumal of Personality and Social Psychology, 77, 167-184

Nisbett, R. E. \& Wilson, T. D. (1977). Telling more than we can know: Verbat reports on mental processes. Psychological Review, 84, 231-259

Oettingen, G., Grant, H., Smith, P. K., Skinner, M., \& Gollwitzer, P. M. (2006). Nonconscious goal pursuit: Acting in an explanatory vacuum. Joumal of Experimental Social Psychology, 42, 668-675.

Riketta, M., \& Dauenheimer, D. (2003). Anticipated success at unconconscious goal pursit: Consequences for mood, self-esteem, and the evaluation of a goalrelevant task. Motivation and Emotion, 27, 327-338.

Robert, C., \& Carnevale, P. J. (1997). Group choice in ultimatum bargaining. Organizationd Behowior and Human Decision Processes, 72, 256-279.

Roser, M., \&azzaniga, M. S. (2004). Automatic brains-Interpretive minds. Current Directions in Psychological Science, 13, 56-59.

Roth, A. E, Malouf, M. W. (1979). Game-theoretic models and the role of information in bargaining. Psychological Review, 86, 574-594.

Russell, J. A. (2003). Core affect and the psychological construction of emotion. Psychological Reviow, 110, 145-172

Schaller, M. \& Cialdini, R. B. (1988). The economics of empathic helping: Support for a mood management motive. Joumal of Experimental Social Psychology. 24 , 163-181.

Schwarz, N., \& Clore, G. L. (1983). Mood, misattribution, and judgments of wellbeing: Informative and directive functions of affective states. Journat of Personality and Social Bychology, 45, 513-523.

Shah, J. Y. (2003). Automatic for the people: How representations of significant others implicitly affect goal pursuit, joumal of Personality and Social Psychology. $84,661-681$.

Shah, J. Y. \& Kruglanski, A. W. (2003). When opportunity knocks: Bottom-up priming of goals by means and its effects on self-regulation. Journal of Personality and Social Psychology, 84, 1109-1122.

Stapel, D. A., \& Koomen, W. (2001). When we wonder what it all means: Interpretation goals facilitate accessibility and stereotyping effects. Personality and Social Psychology Bulletin, 27, 915 929.

Stone, J., \& Cooper, ]. (2001). A self-standards model of cognitive dissonance. Joumal of Experimental social Psychology, 37, 228-243

Sully, J. (1891), Ilasions: A psychological study. New York: D. Appleton and Company.

Wegner, D. M., Sparrow, B., \& Winerman, L. (2004). Vicarious agency: Experiencing control over the movements of others. Joumal of Personality and social Psycholocy, 86, 838-848.

Wilson, T. D., Centerbar, D. B., Kermer, D. A., \& Gibert, D. T. (2005). The pleasures of uncertainty: Prolonging positive moods in ways people do not anticipate. Joumal of Personality and Social Psychology, 88, 5-21.

Zanna, M. P. \& Cooper, J. (1974). Dissonance and the pill: An attribution approach to studying the arousal properties of dissonance. Joumal of Personality and Social Psychology, 29, 703-709.

Zeigarnik, B. (1927). Das Behaiten erledigter und unerledigter Handlungen IOn the recall of conpleted and uncompleted tasks]. Psychologische Forschung, 9, 1-85. 